\author{
Journal of Educational Psychology \\ Issue: Volume 111(5), July 2019, p 793-808 \\ Copyright: (C) 2019 by the American Psychological Association \\ Publication Type: [Learning and Achievement] \\ DOI: $10.1037 /$ edu0000310 \\ ISSN: 0022-0663 \\ Accession: 00004760-201907000-00003 \\ Keywords: imagination, perspective, multimedia learning, learning strategy, reading strategy \\ Show Cover \\ [Learning and Achievement]
}

\title{
The Power of Imagination and Perspective in Learning From Science Text
}

Leopold, Claudia; Mayer, Richard E.; Dutke, Stephan

Section Editor(s): Graham, Steve Editor

\section{Author Information}

Center for Teacher Education, University of Freiburg

Department of Psychological and Brain Sciences, University of California, Santa Barbara

Institute for Psychology in Education, University of Muenster

The research presented in this article was supported by the German Research Foundation.

Claudia Leopold, Center for Teacher Education, University of Freiburg, Rue P.A. de Faucigny 2, CH-1700

Freiburg, Switzerland claudia.leopold@unifr.ch

Received July 10, 2017

revised July 23, 2018

Accepted July 25, 2018

\begin{abstract}
In 2 experiments, college students read a 4-paragraph text on how the human circulatory system works and were instructed to form a mental image of the events described in each paragraph from the perspective of their own body (first-person perspective group) or from the perspective of a fictitious person facing them (third-person perspective group), or were given no imagination instructions (control group). Students who imagined from a first-person perspective outperformed the control group on solving transfer problems, retaining important material, and not retaining unimportant material in Experiments 1 and 2, confirming the benefits of combining imagination and perspective into a powerful learning strategy. Students who imagined from a first-person perspective outperformed students who imagined from a third-person perspective on solving transfer problems in Experiments 1 and 2, indicating the value of adding first-person perspective to imagination for fostering deeper understanding. Students who imagined from a third-person perspective outperformed the control group on solving transfer problems and on not retaining unimportant material in Experiment 1 (which included specific prompts for which items to include in one's images), whereas they did not perform significantly better than the control group on any measures in Experiment 2 (which did not include specific prompts). This finding suggests that imagination without first-person perspective can be ineffective when there is not support for imagining during learning. These findings have theoretical implications for the role of embodiment in generative learning theory, and practical implications for modifying the imagination principle to recommend imagining from a first-person perspective.
\end{abstract}

\section{Imagination and Perspective in Learning From Science Text Objective and Rationale}


Comprehending scientific text can be a challenging task for students, often because they use ineffective reading strategies (Chambliss \& Calfee, 1998; Cromley, Snyder-Hogan, \& Luciw-Dubas, 2010; Otero \& Graesser, 2002). For example, in reading a passage about how the human heart works, students may focus on acquiring discrete facts rather than building a mental model of the circulatory system (Leutner, Leopold, \& Sumfleth, 2009; Oostendorp \& Goldman, 1999). Overall, we expect students in STEM courses to comprehend scientific text, but we seldom equip them with the strategies they need for effective reading.

In light of difficulties that students may face in reading scientific texts, the overarching goal of the present study is to examine how students can best use imagination as a learning strategy that improves their learning from science text. In short, we seek to maximize the effectiveness of imagining as a generative learning strategy. A generative learning strategy is an activity that a learner engages in during learning with the intention of helping learn the material deeply (Fiorella \& Mayer, 2015, 2016b). Imagining is a generative learning strategy for text-based instruction in which the learner forms a mental image that depicts the main processes or structures described in each section of the text.

In particular, the primary goal of the present study is to determine whether students learn more deeply (particularly as measured by transfer test performance) when they are encouraged to a use a first-person imagining strategy for reading a science text on the human circulatory system (first-person perspective group), as compared to receiving no strategy instruction (control group). In a first-person imagination strategy, the learner forms a mental image from the perspective of his or her own body.

A secondary goal is to determine whether students learn more deeply when they are encouraged to use a first-person imagining strategy (first person perspective group) than a third-person imagination strategy (third-person perspective group). In a third-person imagination strategy, the learner forms a mental image as if they are looking at the circulatory system in someone else's body.

A third goal is to determine whether students learn more deeply when they are encouraged to use a thirdperson imagining strategy for reading a science text on the human circulatory system (third-person perspective group), as compared to receiving no strategy instruction (control group); and whether this effect depends on being provided with specific prompts on what to imagine during learning.

The rationale for this study is to determine how best to encourage students to use a generative reading strategy for scientific text rather than a linear reading strategy. A linear reading strategy involves reading sentences and trying to remember them in order, thereby leading to shallow learning (Ponce \& Mayer, 2014). For example, a student who is reading a four-paragraph lesson on how the human circulatory system works, such as shown in Table 1, may employ a common reading strategy of reading every word with a goal of mentally representing the facts as presented (Fiorella \& Mayer, 2015). This is a linear reading strategy, which may help boost performance on tests of retention of isolated details but may not prepare the student to perform well on tests of transfer. Transfer refers to using prior learning to solve new problems, and is a fundamental mission of education (Pellegrino \& Hilton, 2012). When the goal of learning is to promote deep understanding, a linear reading strategy is not optimal. 
Table I

Text on the Blood Circulatory System

The heart is a hollow muscle about the size of a fist. It pumps blood through blood vessels that transport it into all the parts of the body and carry it back to the heart again. Scientists distinguish between two types of blood vessels: arteries and veins. Anteries are blood vessels that earry blood away from the heart. Veins are vessels that carry blood back to the heart again. The arteries branch off into finer arteries throughout the body and finally form a network of tiny blood vessels with thin walls called capillaries. The capillaries then unite again into larger blood vessels- the veins, In this lesson, the heart and the blood circulatory system will be explained. To understand these topics, it is important to know that in biology and medicine scientists distinguish between the left side and the right side of the body such as the left and right hand or the left and the right side of the heart. They base this left-right distinction on the perspective of the person, whose hand or heart is described. The heart of an adult man weighs on average 320 grams and that of a woman 280 grams.

The heart is composed of a right side and a left side which are separated from each other by a dividing wall, called the septum. Each half of the heart consists of two hollow chambers: A smaller atrium that is situated in the upper part and a somewhat bigger chamber, called the ventricle that is located underneath the atrium. Between the atrium and its corresponding ventricle are atrioventricular valves. Similar to the leaves of a one-way swinging door they can only be opened in one direction-inward toward the ventricle. Through the atrioventricular valves the blood flows from the atrium into the ventricle. The valves prevent blood from flowing back from the ventricle into the atrium. When an adult person is in a state of rest his or her heart usually beats about 70 times per minute and pumps about $\mathrm{I}$ and a half gallons of blood.

How does the blood circulatory system work? The muscles of the left ventricle contract and thereby pump oxygen-rich blood (that came from the lungs) out of the ventricle into a big artery, the aorta. The aorta carries the blood to the organs of the body, such as the digestion organs. Within the capillary network of the organs a gas exchange takes place. The blood delivers oxygen to the cells of the boxly organs and picks up carbon dioxide from the body organs. The oxygen-poor blood then flows from the capillaries into venules. These are smaller veins that merge into larger veins. Veins have thinner walls and a larger diameter than arteries. Scientists distinguish superficial veins that are close to the skin from deeper veins of the musculature. The veins carry the blood from the body organs back to the right atrium. This part of the circulatory system is called the systemic circulation system. Schematically it is often shown as being located beneath the heart although in reality the blood is carried to all the organs of the body.

The second part of the circulatory system is called the pulmonary circulation system. Schematically it is often shown as being located above the heart, because the upper parts of the lungs lie somewhat above the heart. The oxygen-poor blood in the right atrium flows through the atrioventricular valves into the right ventricle, from where it is pumped into the pulmonary artery that carries the blood to the lungs. In the capillary nets of the lungs a gas exchange takes place. The blood releases its carbon dioxide and is recharged with oxygen that it absorbs. From the lungs the oxygenrich blood flows through the pulmonary vein back to the left atrium. It then flows through the atrioventricular valves into the left ventricle and can join the systemic circulation, again.

1 Text on the Blood Circulatory System

What can be done to encourage the student to process the lesson more deeply? In order to foster generative cognitive processing-that is, cognitive processing aimed at making sense of the material-we could ask the student to use a generative reading strategy (Ponce \& Mayer, 2014) such as learning by imagining. Learning by imagining involves forming a mental image depicting the key material described in the lesson, and has been recognized as one of eight potentially powerful learning strategies for promoting generative processing during reading from text (Fiorella \& Mayer, 2015, 2016b). For example, in addition to reading each paragraph in the text shown in Table 1, the student may be asked to form a mental image along with a prompt to the right of each paragraph, such as for paragraph 1: "Please imagine how the heart, arteries, capillaries, and veins are connected to each other."

Although learning by imagining can be an effective reading strategy for promoting deep understanding, as measured by transfer tests (Leopold \& Mayer, 2015; Leutner et al., 2009), forming images may be optimized when the student is encouraged to take a first-person perspective rather than a thirdperspective, particularly for embodied content such as a text on the human circulatory as shown in Table 1. For example, Figure 1 provides an example of instruction in how to form first-person (or self-referenced) images, whereas Figure 2 provides an example of instruction in how to form third-person (or external) images. To further encourage imagination from a first-person perspective, we can change the "the" to "your" in the prompt from the previous paragraph, yielding: "Please imagine how your heart, arteries, capillaries, and veins are connected to each other." The following section examines research on generative learning strategies that involve imagining or first-person perspective in helping learners understand scientific text. 
Example "arm":

1. Read the paragraph

The human arm consists of multiple parts: The upper arm extends from the shoulder to the elbow. The elbow is a hinged joint that allows the arm to swing 180 degrees at full extension. The forearm is the area between the wrist and the elbow. Thus muscles in the forearm rotate the wrist.
2. Imagine the parts of your own arm.

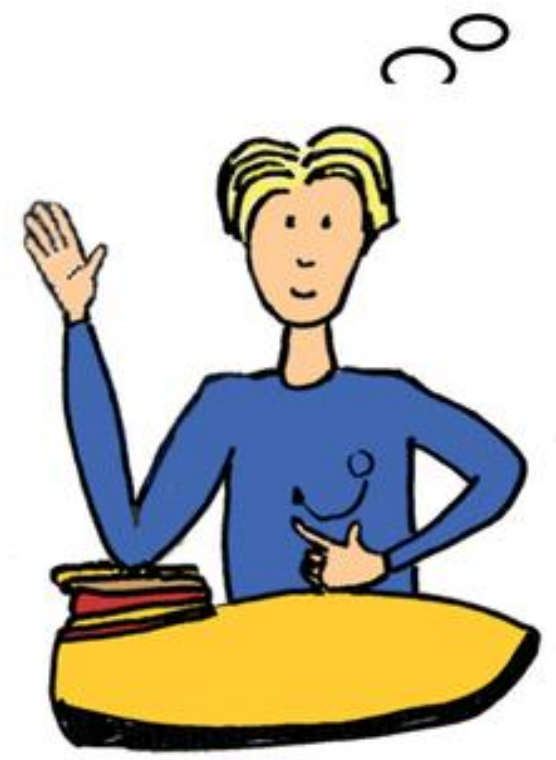

Please read each of the following four paragraphs.

Create images of each paragraph in your head.

Imagine the circulatory system of your own body.

Point with your forefinger to your own body, about what is explained in the text.

1. Instruction sheet for the first-person perspective group (used in Experiment 1). 


\section{Example "arm":}

\section{Read the paragraph}

The human arm consists of multiple parts: The upper arm extends from the shoulder to the elbow. The elbow is a hinged joint that allows the arm to swing 180 degrees at full extension. The forearm is the area between the wrist and the elbow. Thus muscles in the forearm rotate the wrist.

\section{Imagine the parts of the arm of another} person who is facing you.

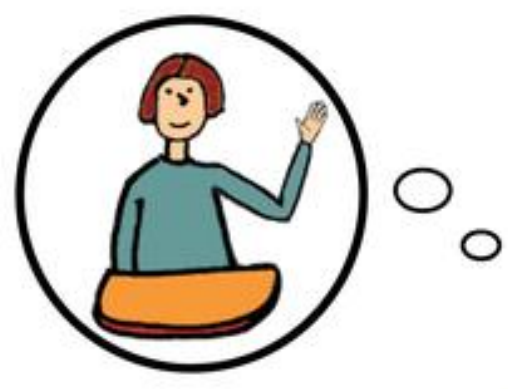

Please read each of the following four paragraphs.

Create images of each paragraph in your head.

Pretend you are sitting in front of someone else and imagine his or her circulatory

system.

2. Instruction sheet for the third-person perspective group (used in Experiment 1).

\section{Literature Review}

Much prior research has focused on instructional design features that improve student comprehension of science text, including techniques for the effective use of graphics (Lowe \& Ploetzner, 2017; Mayer, 2014a), but an alternative approach is to equip learners with effective learning strategies (Fiorella \& Mayer, 2015; Pressley \& Woloshyn, 1995). The motivation for the present study comes from combining two lines of research aimed at fostering generative learning strategies: research on imagination as an aid to learning and research on perspective as an aid to learning. In this section, we explore the case for imaginationasking the learner to form a mental image of the key material in each section of a scientific text-and the case for perspective-asking learners to form mental images from a first-person perspective that involves reference to their own bodies.

\section{The case for imagination}

Research on the role of imagination in STEM (i.e., science, technology, engineering, and mathematics) learning is beginning to yield promising findings that favor the use of imagining as a generative learning strategy (Fiorella \& Mayer, 2015, 2016b). For example, in a classic study involving elementary school, high school, and college students, Rasco, Tennyson, and Boutwell (1975) found that students performed better on a comprehension test if they read an expository text with instructions to form mental images to help remember the information. 
More recently, Leutner et al. (2009) asked high school students to read a 13-paragraph text on water molecules and either imagine an illustration depicting each paragraph (imagination group) or study each paragraph (control group). On a subsequent comprehension test, the imagination group scored substantially higher than the control group $(d=0.57)$, indicating the power of imagination for improving comprehension of science text.

In another study of the role of learning by imagining with science text, Leopold and Mayer (2015) asked college students to read a nine-paragraph lesson on the human respiratory system while they imagined an illustration for each paragraph (imagination group), or read it in their usual way (control group). Across two experiments, the imagination group scored higher on retention tests ( $d s=0.80$ and 0.74 ) and transfer tests $(d s=1.30$ and 0.86 ), again indicating the power of imagination for improving comprehension of science text.

In a recent study, Lin et al. (2017) asked college students to form a mental image after reading an entire nine-paragraph lesson on the human cardiovascular system, or to simply reread the lesson. The imagination group scored higher on a comprehension posttest with an effect size of $d=.33$, but this difference did not reach statistical significance, perhaps because the students did not receive focused instructions on what to imagine after each paragraph.

In another set of studies, middle school students who were high in prior knowledge benefited more than low-knowledge learners from instructions to imagine as they learned about using spreadsheet software (Cooper, Tindall-Ford, Chandler, \& Sweller, 2001) or computer programming (Ginns, Chandler, \& Sweller, 2003). Leahy and Sweller $(2004,2005,2008)$ provided replication support for the idea that high-knowledge elementary school students benefit from instructions to imagine more than low-knowledge students as they learned to read temperature graphs and bus timetables, and that imagination can be a useful learning strategy.

Overall, in a recent review of 22 experiments comparing learning of STEM material with or without an imagination learning strategy, Fiorella and Mayer (2015) reported a median effect size of $d=0.65$ favoring learning by imagining. In short, there is encouraging evidence that imagination can be a powerful learning strategy for STEM material, and for generative learning theory on which generative learning strategies are based. Concerning boundary conditions, there is emerging evidence that the imagination effect is strongest when learners are high in experience or given specific training and support for imagining during learning (Fiorella \& Mayer, 2015).

\section{The case for perspective}

Research on the role of perspective in STEM learning is in its initial stages, but there are encouraging preliminary findings that favor learning from a first-person perspective over a third-person perspective. For example, Fiorella, van Gog, Hoogerheide, and Mayer (2017) asked college students to view a video showing how to construct an electrical circuit on a circuit board. Students performed better on subsequent tests, such as actually constructing the circuit, if the video was filmed from a first-person perspective (with the camera over the shoulder of the builder) than a third-person perspective (with the camera facing the builder).

In a somewhat related line of research, Fiorella and Mayer (2016a) asked college students to view a video in which a lecturer faced the class and explained the Doppler Effect while referring to already drawn illustrations on a whiteboard (i.e., third-person perspective) or to view a video in which the lecturer faced the whiteboard and drew the illustrations by hand while explaining the Doppler effect (i.e., from a firstperson perspective). Students performed better on subsequent transfer tests if they viewed the video in which the lecturer drew while she explained. In this case, the instructor is facing the same direction as the learners as she draws, so the learners may be induced to feel as if they are participating in drawing the illustrations. 
Additional evidence comes from studies on embodiment showing that elementary schoolchildren perform better on reading comprehension tests if they manipulate toys to represent the characters and events in the story as they read, which creates a first-person perspective on the story (Biazak, Marley, \& Levin, 2010; Glenberg, Goldberg, \& Zhu, 2011; Glenberg, Gutierrez, Levin, Japuntich, \& Kaschak, 2004; Rubman \& Salatas Waters, 2000). Along the same lines, Stull, Padalkar, and Hegarty (2017) recently reported that college students learned better from a chemistry lecture if they could hold and manipulate concrete models of molecules along with the lecturer (i.e., from a first-person perspective) rather than simply watch the lecturer manipulate them (i.e., from a third-person perspective). In another line of research (Bokosmaty, Mavilidi, \& Paas, 2017; Vitale, Swart, \& Black, 2014), children's performance on retention tests about geometric shapes was better if students were allowed to manipulate the shapes (i.e., from a first-person perspective) rather than observe them being manipulated (i.e., from a third-person perspective).

More broadly, perspective has been shown to play a role in science and math instruction involving demonstrations with concrete manipulatives (Marley \& Carbonneau, 2015) and has been identified as a consideration in the construction of instructional videos (Lindgren, 2012). Gerofsky (2010) found that the viewpoint from which a student gestures during explaining a mathematical concept is an indication of understanding, and in a series of ethnographic studies, Goldman-Segall (1998/2014; Goldman-Segall \& Maxwell 2003) also found that point of view is an important aspect of learning and instruction.

Overall, there are emerging pockets of research suggesting that learning is improved when learners can take a first-person perspective rather than a third-person perspective. The present study is intended to contribute to this developing research base and to theories of embodiment upon which they are based (Fiorella \& Mayer, 2015).

In the next section, inspired by these research bases on learning by imagining and on the role of firstperson perspective, we offer a theoretical case for combining them into a more powerful kind of generative learning strategy.

\section{Theory and Predictions}

The goal of this study is to bring together these two emerging techniques for promoting deep learning of scientific systems-learning by imagining and taking a first-person perspective. In short, the present study seeks to determine the benefits of combining two potentially powerful aids to learning-imagination and perspective.

\section{Generative learning theory}

The theoretical rationale for imagination as an aid to learning rests in generative learning theory. Generative learning theory holds that learners actively construct knowledge in working memory by engaging in appropriate cognitive processing during learning, including selecting relevant aspects of the incoming information for further processing, mentally organizing relevant incoming material into a coherent structure, and integrating incoming material with relevant existing knowledge activated from long-term memory (Fiorella \& Mayer, 2015, 2016b).

In learning by imagining, each of the three cognitive processes for generative learning is activated. First, the learner is required to select relevant components of the to-be-learned system to include in the mental image, which primes the process of selecting in generative learning theory. Second, the learner is required to spatially arrange the components in the mental image, which primes the process of organizing in generative learning theory. Third, the learner is required to relate the text material to prior knowledge through translating from verbal to visual forms of representation, which primes the process of integrating in generative learning theory. 
Generative learning theory has its roots in Piaget's (1926) analysis of cognitive change based on assimilation and accommodation, Bartlett's (1932) constructive conception of learning as assimilation to schema, and classic Gestalt distinctions between meaningful and rote learning (Wertheimer, 1959). The current version of generative learning theory meshes with information processing conceptions of learning (Mayer, 2014b), in which knowledge construction takes place in a working memory that has limited processing capacity.

Wittrock (1974, 1989; Mayer \& Wittrock, 2006) showed how generative learning can be applied to academic learning and instruction, whereas Fiorella and Mayer (2015, 2016b) showed how it can be applied to learning strategies that foster meaningful learning. According to a recent review by Fiorella and Mayer (2015, 2016b), imagination is one of eight generative learning strategies that have been shown to increase student learning, including learning from science text, because it fosters generative cognitive processing. According to generative learning theory, these kinds of generative processes can be primed by asking learners to imagine illustrations that correspond to a science text they are reading.

\section{Embodiment theory}

The theoretical rationale for considering the role of perceptual perspective in learning draws on theories of embodied learning (Glenberg, 2008; Robbins \& Aydede, 2009; Shapiro, 2014). The underlying idea-which can be called the embodiment thesis-is that "cognition depends not just on the brain also the human body" (Robbins \& Aydede, 2009, p. 3). Research on gesture supports this idea and suggests a role for perspective in science learning (Goldin-Meadow \& Beilock, 2010: Kontra, Goldin-Meadow, \& Beilock, 2012). Although support for embodiment theory is somewhat diverse (as exemplified in the foregoing review of the role of perspective in learning), the overarching theme is that people learn with their whole body, including when they learn from reading science text by participating physically with the material in the lesson.

At its most general level, embodiment theory is concerned with "how the body shapes the mind" (Gallagher, 2005, p. 1) and holds that cognition is "dependent on the situation or context in which it occurs" (Robbins \& Aydede, 2009, p. 3). However, work is needed to articulate and apply embodiment theory at a more specific level that proposes cause-and-effect mechanisms. As a step in this direction, we focus on physical self-reference as a possible mechanism for embodiment theory, in which people learn more deeply when they can easily relate academic content to their own body. When material is presented or imagined from a third-person perspective, learners must mentally transform the representation into their own perspective (Fiorella et al., 2017). In contrast, when material is presented or imagined from a firstperson perspective, physical self-reference is more easily primed without the need for mental transformations.

Although people have the ability to take the spatial perspective of others, carrying out the needed mental transformations can be cognitively demanding (Fiorella et al., 2017; Hegarty \& Waller, 2004). Thus, viewing or imagining from a third-person perspective can create extraneous cognitive load that detracts from the processing resources available to understand the content, whereas viewing or imagining from a firstperson perspective does not create this same high level of extraneous cognitive load, thereby allowing more processing capacity for making sense of the material. 
Some scholars have attributed the benefits of first-person perspective to the activation of the human mirror neuron system (Rizzolatti \& Craighero, 2004; van Gog, Paas, Marcus, Ayres, \& Sweller, 2009). For example, research using functional MRI (fMRI) compared students who viewed videos of simple hand and foot actions presented from a first-person perspective or a third-person perspective (Jackson, Meltzoff, \& Decety, 2006). First-person perspective created more brain activation in areas related to making the action and subsequently fostered faster response times to imitate the action than did third-person perspective. Such results are consistent with embodied views of cognition (Robbins \& Aydede, 2009), by suggesting that videos from a first-person perspective encourage learners to feel as if they are actually engaging in the depicted actions, in contrast to videos filmed from a third-person perspective.

Alternatively, first-person perspective may create a sense of self-reference that helps the reader find value and interest in the material, which in turn may motivate learners to exert greater effort or engagement (Renninger \& Hidi, 2016). Motivational theories based on value (Wigfield, Tonks, \& Klauda, 2016) and interest (Alexander \& Grossnickle, 2016) are compatible with embodied conceptions of learning, in which self-reference may initiate a form of situational interest that creates curiosity and helps the learner see personal value in understanding the material in the lesson.

When applied to academic learning situations involving text-based STEM lessons, embodiment theory suggests using the generative learning strategy of learning by enacting-that is, acting out the material in a lesson by using concrete objects (Fiorella \& Mayer, 2015, 2016b; Glenberg, 2008). Furthermore, when combined with the learning strategy of learning by imagining, embodiment theory suggests that imagination will be most successful when it allows learners to imagine carrying out manipulations with their own hands from their first-person perspective. In short, first-person perspective is more likely to allow learners to use their bodies in interacting with the content of a lesson.

\section{Predictions}

In this study we examine whether we can increase the effectiveness of imagination as a learning strategy by also incorporating first-person perspective in the learner's imagination process. Based on generative learning theory and embodiment theory, we derive three predictions:

Hypothesis 1: Students in the first-person perspective group will learn more deeply than students in the control group, as indicated primarily by higher transfer test performance and drawing test performance (Hypothesis 1a), and secondarily by a pattern of higher retention of important facts (Hypothesis 1b) and lower retention of unimportant details (Hypothesis 1c). In short, the primary goal of this study is to test the idea that being encouraged to use a learning strategy that combines imagination and perspective will promote deeper learning than receiving no strategy guidance.

Hypothesis 2: Students in the first-person perspective group will learn more deeply than students in the third-person perspective group, as indicated primarily by higher transfer test performance and drawing test performance (Hypothesis 2a), and secondarily by a pattern of higher retention of important facts (Hypothesis 2b) and lower retention of unimportant details (Hypothesis 2c). In short, a second goal of this study is to test the idea that using a learning strategy that combines imagination and perspective will promote deeper learning than using a learning strategy that involves only imagination (without first-person perspective).

Hypothesis 3: Students in the third-person perspective group will learn more deeply than students in the control group, particularly when given support during learning (i.e., in Experiment 1 rather than Experiment 2), as indicated primarily by higher transfer test and drawing test scores (Hypothesis 3a), and secondarily by a pattern of higher retention of important facts (Hypothesis $3 b$ ) and lower retention of unimportant details (Hypothesis 3c). In short, a third goal of this study is to determine whether using what may be a suboptimal imagination strategy can lead to deeper learning than getting no strategy guidance, at least when the lesson provides support for imagining in the form of specific prompts. 


\section{Experiment 1 (High Support)}

In Experiment 1, college students in the United States read a paper-based text on how the human circulatory system works and subsequently took transfer, drawing, and retention tests. For each of four paragraphs in the lesson, students were instructed to form a mental image of the processes described in the text from the perspective of their own body (first-person perspective group) or from the perspective of a fictitious person facing them (third-person perspective group), or given no imagination instructions (control group). In Experiment 1, students were given specific imagery prompts for each paragraph in the two imagination groups, such that they were told which components to include in their mental illustration. The first experiment allows us to test our predictions in a situation in which the two imagination groups are given support for forming images during learning.

\section{Method}

\section{Participants and design}

The participants were 81 English-speaking college students recruited from a university in the western United States. Students fulfilled a course requirement by participating in the experiment. Their mean age was 19.68 years $(S D=1.67)$, and the percentage of female students was $67.90 \%$. Only students who scored low on a prior knowledge test about blood circulation (i.e., who scored less than $50 \%$ on a prior knowledge test) were included. We used $50 \%$ as the cut-off because scores above $50 \%$ required detailed specific knowledge. We focused on low-knowledge learners because these are the most common participants and because we wanted our findings to be most applicable in introductory-level STEM instruction. Data for 2 students were not scored or included in our sample of 81 students because they scored high on prior knowledge and we sought determine if we could improve learning in inexperienced learners. The decision to exclude was done before scoring the tests. Twenty-eight students served in the first-person perspective group, 27 in the third-person perspective group, and 26 in the control group.

\section{Learning materials}

All materials were in English. The learning materials consisted of a scientific text on how the human blood circulatory system works, as shown in Table 1 . The text contained 649 words organized into four paragraphs, with each paragraph printed on an $8.5 \times 11$-in. sheet of paper. The text integrated information from biology and anatomy textbooks about the structure and function of the human heart. In the first paragraph, the reader was introduced to different types of blood vessels, such as arteries, veins, and capillaries, and was informed that scientists in biology and medicine distinguish between the left side and the right side of the body based on the perspective of the person whose body is described. In the second paragraph the structure of the heart was described, including the four chambers and valves between them. The third paragraph described the systemic circulatory system, which connects with the heart. The fourth paragraph described the pulmonary circulatory system, which connects with the lungs. In addition, we inserted four unimportant details into the text, which are not related to the flow of blood but rather focus on extraneous pieces of information that are not intended to attract interest (e.g., the weight of the heart of an adult person). 
Three versions of instruction sheets were created explaining how to study the text. In the control group, students were asked to read the text paragraph by paragraph and to acquire knowledge from the text as they normally do. In the first-person perspective group, students were asked to read the text and to create images of what is described in each paragraph in their mind as they read. Students were asked to imagine the circulatory system from the perspective of their own body and to point with their forefinger to their own body, as they envisioned the text. As shown in Figure 1, an example was provided to ensure that the students understood the instructions for imagining from a first-person perspective. In the third-person perspective group, students were asked to read the text and to create mental images of each paragraph in their mind. Students were asked to pretend they were sitting in front of someone else and imagine that person's circulatory system. As shown in Figure 2, an example was provided to ensure that the students understood the instructions for imagining from a third-person perspective. We used a human arm as an example in the instructions because we wanted to use a part of the body with clear left-right distinctions but did not want to provide hints about how to visualize the specific content of the lesson. The instructions asked students to point in the first-person perspective group in order to encourage embodiment and self-reference, and did not ask for pointing in the third-person perspective group because we did not want to encourage embodiment and self-reference. In addition, we asked students to point as they imagined in the first-person perspective group because we did not want students to be confused about the somewhat unusual task of imagining their own circulatory system, whereas we did not ask students to point in the third-person perspective group because we thought this task was more straightforward. We told students in both conditions that they did not have to imagine the exact position of the organs, but that it was the relations among them that was important. However, results should be interpreted in light of this difference between the groups, and future research is needed to isolate the effects of pointing on learning.

To provide a high level of imagination support, the first-person perspective group and the third-person perspective received additional imagination prompts to the right of each text paragraph. For example, the first-person perspective group received this prompt to the right of the first paragraph: "Please imagine how your heart, arteries, capillaries and veins are connected to each other." Similarly, the third-person perspective group received this prompt to the right of the first paragraph: "Please imagine how the heart, arteries, capillaries and veins are connected to each other." The control group received the same material except that no imagination prompts were added to the right of each paragraph. The four paragraphs of the text were presented in a booklet with each paragraph presented on a new page.

\section{Test materials}


The test materials consisted of a prior knowledge test, transfer test, drawing test, and retention test, each printed on $8.5 \times 11$-in. sheets of paper. The first page of the prior knowledge test included demographic questions concerning the student's age, gender, and academic major. On the second page, five completion questions followed: "I know the approximate amount of blood an adult person has. That is ," "I can explain the meaning of the concept 'systole'. Systole means ___," "I can explain the meaning of the concept 'diastole.' Diastole means___," "I know the difference between venous and arterial blood. The difference is ___,," and "I can explain what a sinoatrial node is. A sinoatrial node is ." The test was used to determine the students' general prior knowledge about the heart and blood circulatory system. Below each question, space was provided for the students' answers. The students' answers were compared with the correct answers by two raters and were awarded with 2 points when accurate, 1 point when partly accurate, or 0 points when inaccurate or missing. Thus, the maximum number of points was 10 . The interrater reliability was $r=.87$. The items on the prior knowledge test were modeled after similar tests used in dozens of previous experiments (Mayer, 2009). We did not test the students' knowledge of the concepts that were explained in the text, because we did not want to prompt the students to focus on these concepts when reading the test. Previous work on the testing effect has shown that the act of taking a test is a learning event that can be considered a form of learning strategy (Dunlosky, Rawson, Marsh, Nathan, \& Willingham, 2013), and we wanted to avoid creating a testing effect or introducing an additional learning strategy in this study. We did not use a standardized test of reading comprehension because our focus is on learners' familiarity with the topic rather than general reading ability.

The transfer test consisted of five questions, printed on separate sheets, each requiring the students to apply their knowledge to new problems, such as the following: "Suppose you discover that the blood in the left atrium does not contain enough oxygen. What could be the reason for that? What could be done to help the person?" "What would happen if the atrioventricular valves in the right side of the heart would open to both directions?" "Suppose someone has an illness which causes the walls of the arteries to suddenly get thicker and therefore tighter. What effects could this have for the blood circulatory system?" The last question was developed by Butcher (2006) and was slightly reformulated for our study. We computed a transfer score for each participant by counting the number of acceptable answers across the five transfer questions. For example, some acceptable answers for the first question were increase the velocity of blood flow, have the heart pump with higher pressure, and increase the heartbeat rate. The scores ranged between 2 and 21 points $(S D=4.23)$. Two raters coded the students' answers with an interrater reliability of $r=.94$. The internal consistency of the transfer test (Cronbach's alpha $=.61$ ) was lower than acceptable (in both Experiment 1 and Experiment 2), perhaps because the test was intentionally constructed to have qualitatively different kinds of open-ended questions with multiple acceptable answers rather than as a set of equivalent items tapping individual facts and procedures.

The drawing task consisted an $8.5 \times 11$-in. sheet of paper with the following instruction: "Please draw a picture of the blood circulatory system and label the different parts." Students were informed that sketching the important components and the flow of blood in the system would be sufficient rather than drawing aesthetically appealing pictures. The accuracy of the drawing was assessed by coding the accuracy of the students' drawings based on a checklist, which consisted of six criteria based on the organs involved and their spatial relations. The six criteria were (1) the heart with four chambers, (2) the lungs and at least one other body organ, (3) the heart-to-organ connection, (4) the organ-to-heart connection, (5) the heart-to-lungs connection, (6) the lungs-to-heart connection. For an accurate drawing of the particular component, 2 points were given, a partly accurate drawing was given 1 point, and an unacceptable drawing received 0 points. With regard to the heart-to-lungs connection, for example, two points were given when the drawing showed that the right ventricle of the heart was connected to the lungs (by arrows or a line). One point was given when the drawing showed a connection between the heart and the lungs but it was not evident that the right ventricle was connected to the lungs. When the drawing showed an incorrect connection or no connection at all, 0 points were given. The maximal number of points to be achieved in the drawing task was 12 . Two raters scored $25 \%$ of the drawings with an interrater reliability of $r=.97$, and Cronbach's alpha was .84. 
The retention test contained the following directions at the top of the sheet: "Using what you learned in this session, please write an explanation of how the blood circulatory system works." For scoring the students' retention of the important material (important retention score), we divided the text into 31 idea units based on the way the blood flows through the blood circulatory system. For scoring of students' retention of the unimportant material (i.e., unimportant retention score), we focused on four idea units that described particular details mentioned in the text but were not relevant for understanding the process of blood circulation. The important and unimportant idea units were established through discussion and consensus between the authors, based on a model of how the blood circulatory system works. We computed an important retention score for each student by counting the number of important ideas that the student included in his or her explanation, with one point given for correctly stating each of the 31 idea units, for example, "from heart blood is pumped into artery," "artery is called Aorta," "blood is pumped from ventricle into artery," "blood is pumped from left ventricle," "now blood is oxygen-rich," "blood is transported to the organs of body," "to capillary network (of the organs)," and "there a gas exchange takes place." We computed an unimportant retention score by counting the number of extraneous details the student included in his or her explanation. The four unimportant idea units were "an adult man's heart weighs on average 320 grams," "an adult woman's heart weighs on average 280 grams," "the heart beats about 70 times per minute," and "the heart pumps about 1 and a half gallons of blood (= 5 liter per minute)." All scoring was done by two independent raters who were blind to the hypotheses and the experimental condition. Separate scores for important material and unimportant material were computed in order to determine whether the effects of imagining help students to focus on important information instead of trying to process the text as bits and pieces by focusing on extraneous details. Interrater reliabilities were $r=.99$ for the important retention score (Cronbach's alpha $=.91$ ) and $r=1.00$ for the unimportant retention score (Cronbach's alpha $=.78)$.

\section{Procedure}

Students were randomly assigned to the three experimental groups and were tested in groups of 1 to 5 per session, with all participants in a session assigned to the same experimental condition. Students were seated in individual cubicles without visual contact with other participants. First, the students read and signed the informed consent sheet. Next, the experimenter asked the students to complete the first page of the prior knowledge test by filling in personal information regarding their age, gender, and academic major. Then, the experimenter informed the students that they would receive a lesson on the human blood circulatory system, and asked the students to write down the answer for each of the five completion questions on the prior knowledge test. The students were told that we did not expect them to know all the answers and to leave the respective fields empty when they do not know the correct answer. After 5 min the experimenter collected the prior knowledge test.

Next, the experimenter handed the appropriate instruction sheet to each student, asked the students to read the instructions, and then guided the students through the instruction sheet. Students in the thirdperson perspective group were told to read the text on the blood circulatory system and to create images of each paragraph in their mind. They were told to pretend that they are sitting in front of someone else and to imagine his or her circulatory system. Students in the first-person perspective group were told to read the text on the blood circulatory system and to create images of each paragraph in their mind. They were told to imagine the circulatory system with respect to their own body and to point with their forefinger to their own body about what is described in the text (to ensure they followed the instructions). Students in the control group were told to read the text on the blood circulatory system and to acquire knowledge out of the text as they normally learn. All students were informed that afterward they would be asked to answer some questions about the text. The students kept the instruction sheet and could look at it whenever they wished. Students were given the text to study for $8 \mathrm{~min}$, and thereafter the text and the instruction sheet were collected. 
Next, the instructor distributed the retention sheet, which asked the students to write an explanation of how the human blood circulatory system works. After 6 min the retention sheet was collected and the five transfer sheets were presented one at a time. Students were given 3 min for each transfer question. Each transfer sheet was collected by the experimenter before the next sheet was presented. Next, students were given the drawing test sheet and allowed to work on it for $3 \mathrm{~min}$. Finally, the students were thanked for their participation. Throughout the experiment, we complied with guidelines for the treatment of human subjects and received IRB approval.

\section{Results and Discussion}

\section{Are groups equivalent on basic characteristics?}

A preliminary step is to determine whether the groups were equivalent on basic characteristics. Analysis of variance (with $p<.05$ ) showed that the groups did not differ on their prior knowledge or age $(F s<1)$. A chi-square test revealed that there was no difference in the proportion of males and females in the groups $\left([\mathrm{chi}]^{2}=1.65, p=.437\right)$. We conclude that random assignment helped produce groups that were equivalent on these basic characteristics.

\section{Does the first-person perspective group learn more deeply than the control group?}

The primary hypothesis is that students will learn more deeply if they are asked to engage in imagining from a first-person perspective as they read a science text. The first column of Table 2 shows each group's mean transfer score (and standard deviation). We assume that if a group scores significantly higher on a posttest, then that group learned more. An analysis of variance revealed a significant overall effect of the treatment, $F(2,78)=12.36, M S E=11.64, p<.001$, $^{\text {eta }}{ }^{2}=.24$. Consistent with Hypothesis 1a, Dunnett's tests revealed that the first-person perspective group outperformed the control group at $p<$ $.001(d=1.30)$. We used the Dunnett to test predictions that involved comparing each treatment group against the control group, because it is designed to compare each treatment group against the control group.

Table 2

Mean Test Scores and Standard Deviations for Three GroupsExperiment I (High Support)

\begin{tabular}{|c|c|c|c|c|c|c|c|c|}
\hline \multirow[b]{2}{*}{ Group } & \multicolumn{2}{|c|}{ Transfer } & \multicolumn{2}{|c|}{ Drawing } & \multicolumn{2}{|c|}{$\begin{array}{l}\text { Important } \\
\text { retention }\end{array}$} & \multicolumn{2}{|c|}{$\begin{array}{l}\text { Unimportant } \\
\text { retention }\end{array}$} \\
\hline & $M$ & $S D$ & $M$ & $S D$ & $M$ & $S D$ & $M$ & $S D$ \\
\hline First-person & $10.04^{*}$ & 3.99 & $6.75^{\circ}$ & 3.36 & $13.18^{*}$ & 7.15 & .32 & .90 \\
\hline Third-person & 7.59 & 3.02 & 4.96 & 3.18 & 9.37 & 6.83 & .33 & .78 \\
\hline Control & 5.42 & 3.11 & 3.69 & 3.40 & 6.77 & 5.62 & .96 & 1.25 \\
\hline
\end{tabular}

Note. Bold indicates significant difference from control group. Asterisk ()) indicates significant difference from third-person perspective group.

2 Mean Test Scores and Standard Deviations for Three Groups-Experiment 1 (High Support)

The second column of Table 2 shows each group's mean drawing score (and standard deviation), which like the transfer test is intended to measure deep learning. An analysis of variance with type of instruction (first-person, third-person, and control) as a between-subjects factor showed a significant effect of treatment group on the drawing measure, $F(2,78)=5.81, M S E=11.00, p=.004$, [eta ${ }^{2}=.13$. Dunnett's tests revealed that the first-person perspective group outperformed the control group at $p=.002(d=$ 0.91) on the drawing score, also consistent with Hypothesis 1a. Together these results show that the firstperson perspective group displayed deeper learning than the control group by being better able to apply what they learned to new situations. 
The next two columns of Table 2 show each group's mean scores on retention of important and unimportant material (and their standard deviations). A multivariate analysis of variance with type of instruction (first-person, third-person, and control) as the between-subjects factor and the type of retention (important and unimportant) as dependent variables revealed an overall effect of the treatment, Wilks's lambda $=.815, F(4,154)=4.16, p=.003$, partial $[\mathrm{eta}]^{2}=.10$. Univariate analyses showed a significant effect of the treatment on important retention, $F(2,78)=6.49, M S E=43.42, p=.002$, [eta] ${ }^{2}=$ .14 and on unimportant retention, $F(2,78)=3.60, M S E=0.99, p=.032$, [eta ${ }^{2}=.08$. For important retention score, consistent with prediction 1b, Dunnett's tests revealed that the first-person perspective group outperformed the control group at $p=.001(d=1.00)$. For unimportant retention score, consistent with prediction 1c, Dunnett's tests showed that the first-person group included fewer extraneous details than the control group did, $p=.038(d=.60)$. Thus, the first-person perspective group displayed a pattern consistent with the idea that they learned more deeply by focusing more on important material and less on unimportant material as compared to the control group.

Although the Dunnett's test is the most appropriate post hoc test because our main goal was to compare each treatment group to the control group, in the interests of completeness we also conducted Tukey's HSD post hoc tests with alpha set at .05 for the data in Experiment 1 (in Table 2). For each of the four dependent measures in Table 2, the first-person group performed significantly better than the control group, and none of the other pairwise comparisons was significant. Also, in the interests of completeness, we recalculated each of the foregoing ANOVAS (on transfer, drawing, and retention) as ANCOVAs with prior knowledge as a covariate. In each case the main effect of treatment group remained statistically significant.

Overall, these results point to the power of combining imagination and perspective in promoting deep learning. This is the main new contribution of this study.

\section{Does the first-person perspective group learn more deeply than the third-person perspective group?}

The foregoing section showed that combining imagination and perspective produced a powerful learning strategy that promoted deeper learning. A further issue, addressed in Hypothesis 2, is whether combining imagination and perspective is more effective than imagination alone. We used $t$ tests because we wished to test specific predictions involving the comparison of two treatment groups. For transfer performance the first-person perspective group outperformed the third-person perspective group, $t(53)=2.56, p=$ $.013, d=.70$, supporting Hypothesis $2 \mathrm{a}$, and the first-person perspective group outperformed the thirdperson perspective group on the drawing score, $t(53)=2.02, p=.048, d=.55$, also consistent with Hypothesis $2 a$. In addition, $t$ tests revealed that the first-person perspective group outperformed the thirdperson perspective group for important retention, $t(53)=2.02, p=.049, d=.55$, supporting Hypothesis $2 \mathrm{~b}$, but the groups did not differ significantly on unimportant retention, $t(53)<1$, in contrast to Hypothesis 2c. These results indicate that imagining the blood circulatory system from a first-person perspective helps learners focus on important information concerning the cause-and-effect system and leads to better transfer performance than imagining it from a third-person perspective. Overall, there is evidence that the power of imagination can be increased by adding the power of first-person perspective. This is a new contribution of this study. However, this conclusion should be tempered by the fact that the first-person group was asked to point whereas the third-person group was not.

\section{Does the third-person perspective group learn more deeply than the control group?}


The third hypothesis is that the third-person perspective group will learn more deeply than the control group, reflecting previous research showing a positive effect of asking students to imagine as they learn. Consistent with Hypothesis 3a, Dunnett's tests revealed that the third-person perspective group outperformed the control group on the transfer test, $p=.043(d=.71)$, although for the drawing test, the third-person perspective group did not outperform the control group, $p=.281$. There was also a pattern in which the first-person perspective group remembered less of the unimportant material than the control group, $p=.045(d=.62)$, as predicted with Hypothesis 3c, but the third-person perspective group did not outscore the control group in remembering important information, $p=.262$, in contrast to Hypothesis $3 \mathrm{~b}$. Overall, there is partial support for the prediction that students learn more deeply when they engage in imagining during learning, even when it is from a third-person perspective. These results support the power of imagination in promoting deep learning, and add replication support to previous findings showing the benefits of learning by imagining.

\section{Summary}

The left half of Table 3 summarizes the results of Experiment 1 concerning the three research hypotheses, by presenting the effect sizes based on Cohen's $d$ for each of three pairwise comparisons (with significant differences indicated in boldface). The first row summarizes the evidence for Hypothesis 1, which predicts that the first-person group outperforms the control group on each of the four measures. As can be seen, the differences favoring the first-person perspective group are all statistically significant and the effect sizes are mainly in the large range, yielding strong support for Hypothesis 1 . The second row summarizes the evidence for Hypothesis 2, which predicts that the first-person group outperforms the third-person group on each of the four measures. As can be seen, there are three significant differences favoring the first-person group, and they produced effect sizes in the medium to large range. Finally, the third row of Table 3 summarizes the evidence for Hypothesis 3, which predicts that the third-person perspective group outperforms the control group on all four measures. As can be seen, two of the four measures yielded significant differences favoring the third-person perspective group over the control group, with effect sizes in the medium to large range. Overall, there is strong support for Hypothesis 1 and Hypothesis 2, which demonstrates that imagining from a first-person perspective is a powerful and superior learning strategy, and partial support for Hypothesis 3, which offers some evidence for the value of imagination as a learning strategy even when it is from a third-person perspective.

Table 3

Effects Sizes for Three Hypotheses About Imagination and Perspective

\begin{tabular}{|c|c|c|c|c|c|c|c|}
\hline \multirow[b]{2}{*}{ Hypothesis } & \multicolumn{4}{|c|}{$\begin{array}{l}\text { Experiment } 1 \\
\text { (High support) }\end{array}$} & \multicolumn{3}{|c|}{$\begin{array}{l}\text { Experiment } 2 \\
\text { (Low support) }\end{array}$} \\
\hline & Tran 1 & Draw & Impt & Unimpt & Tran & Impt & Unimpt \\
\hline First-person > control & 1.30 & .91 & 1.00 & .60 & .51 & .86 & .71 \\
\hline First-person $>$ third-person & .69 & .55 & .54 & .01 & .48 & .37 & .40 \\
\hline Third-person > control & .71 & .39 & .42 & .62 & .07 & .47 & .46 \\
\hline
\end{tabular}

Note. Tran $=$ better score on transfer test; Draw $=$ better score on drawing test; Impt $=$ higher retention of important material; Unimpt $=$ lower retention of unimportant material. Boldface indicates significant difference at $p<.05$. Numbers in table are Cohen's $d$.

3 Effects Sizes for Three Hypotheses About Imagination and Perspective

\section{Experiment 2 (Low Support)}


Experiment 1 helped establish the idea that imagining from a first-person perspective could be an effective generative learning strategy when heavy amounts of support were provided in terms of specifying the components to include in forming images for each paragraph. Experiment 2 was similar to Experiment 1 except (1) students in the imagination groups were not given specific prompts about which components to put in their imagined illustrations, (2) the tests were streamlined, with fewer transfer test items and no drawing test, and (3) the students were in Germany and the materials were in German. The goal was to determine the degree to which the results of Experiment 1 could be replicated in a learning context involving low support of imagination during learning and in a different university with different participants. It is worthwhile to determine the robustness of the self-referenced imagination effect, particularly whether it still works for college students when less direction is given for what to include in their self-referenced images. Thus, Experiment 2 is a form of replication study (as called for by Shavelson \& Towne, 2002) intended to determine whether imagining from a first-person perspective works in a different context than in Experiment 1 (e.g., with less instructional support for imagining but also some other methodological differences).

\section{Method}

\section{Participants and design}

The participants were 75 German-speaking students from different departments of a German University. Participants were paid for their participation. Their mean age was 23.97 years $(S D=3.83)$, and the percentage of female students was $61.3 \%$. As in Experiment 1, only students who scored low on a prior knowledge test about blood circulation (less than $50 \%$ of the points on a pretest) were included. This resulted in data for 16 students not being included in the sample of 75 students reported in this article on the grounds that they scored high in prior knowledge. Although the tests were scored for these students, the decision to exclude was intended to be consistent with Experiment 1. The number of high-knowledge learners may have been greater in Experiment 2 because the participants were older. The study was based on a between-subjects design with three levels of mental imagery instruction: first-person perspective group ( $n=26)$, third-person perspective group $(n=25)$, and control group $(n=24)$. This experiment provided low support for imagination during learning because there were no prompts stating which elements to include in one's image for each paragraph.

\section{Materials}

The materials were the same as in Experiment 1 except for five differences. First, the materials were in German. Second, the learning materials for the first-person perspective group and the third-person perspective group did not include prompts to the right of each paragraph telling students which elements to include in their images. Third, the transfer test consisted of four items rather than five. Fourth, there was no drawing test. Fifth, the size of sheets of paper was $21 \times 30 \mathrm{~cm}$. Interrater reliabilities were $r=.97$ for transfer test score (Cronbach's alpha $=.52), r=.98$ for the important retention score (Cronbach's alpha $=$ $.84)$, and $r=.99$ for the unimportant retention score (Cronbach's alpha $=.74$ ).

\section{Procedure}

The procedure was the same as in Experiment 1 except there was no drawing test. The tests were scored with the same procedures used in Experiment 1.

\section{Results and Discussion}

\section{Are the groups equivalent on basic characteristics?}

Before testing the main hypotheses, we examined whether the three treatment groups were equivalent with regard to prior knowledge, age, and gender distribution. No between-groups differences were found for prior knowledge score $(F<1)$, age $(F<1)$ and for the proportion of males and females per group ([chi] $]^{2}$ $<1)$. Overall, we conclude that the groups were equivalent on these basic characteristics.

\section{Does the first-person perspective group learn more deeply than the control group?}


The primary hypothesis is that students will learn more deeply if they are asked to engage in imagining from a first-person perspective as they read a science text. The first column of Table 4 shows each group's mean transfer score (and standard deviation). An analysis of variance revealed no significant overall effect of treatment, $F(2,72)=2.38, M S E=17.23, p=.100$, [eta $]^{2}=.06$. As the Dunnett's test is a more focused test and valid even if the overall analysis of variance did not find a significant difference among means, we tested comparisons with the control group. Dunnett's tests revealed that the firstperson perspective group outperformed the control group at $p=.046(d=0.51)$, consistent with Hypothesis 1a.

Table 4

Mean Test Scores and Standard Deviations for Three GroupsExperiment 2 (Low Support)

\begin{tabular}{|c|c|c|c|c|c|c|}
\hline \multirow[b]{2}{*}{ Group } & \multicolumn{2}{|c|}{ Transfer } & \multicolumn{2}{|c|}{$\begin{array}{l}\text { Important } \\
\text { retention }\end{array}$} & \multicolumn{2}{|c|}{$\begin{array}{l}\text { Unimportant } \\
\text { retention }\end{array}$} \\
\hline & $M$ & $S D$ & $M$ & $S D$ & $M$ & $S D$ \\
\hline First-person & $12.82^{\circ}$ & 3.79 & 16.46 & 4.44 & .04 & .20 \\
\hline Third-person & 10.96 & 3.90 & 14.60 & 5.61 & .16 & .37 \\
\hline Control & 10.67 & 4.68 & 11.71 & 6.59 & .50 & 1.10 \\
\hline
\end{tabular}

Note. Bold indicates significant difference from control group. Asterisk $\left.{ }^{*}\right)$ indicates significant difference from third-person perspective group.

4 Mean Test Scores and Standard Deviations for Three Groups-Experiment 2 (Low Support)

The next two columns of Table 4 show each group's means (and standard deviations) on retention of important and unimportant material, respectively. A multivariate analysis of variance with type of instruction (first-person, third-person, control) as the between-participants factor and the important retention and unimportant retention scores as dependent variables revealed an overall effect of the treatment, Wilks's lambda $=.840, F(4,142)=3.24, p=.014$, partial [eta] ${ }^{2}=.08$. Univariate analyses showed a significant effect of treatment on important retention, $F(2,72)=4.39, M S E=31.01, p=.016$,

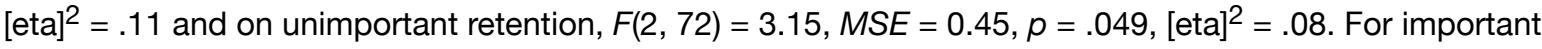
retention score, Dunnett's tests revealed that the first-person perspective group outperformed the control group at $p=.008(d=0.86)$, consistent with Hypothesis $1 \mathrm{~b}$; for unimportant retention score, Dunnett's tests showed that the first-person perspective group included fewer extraneous details than the control group did, $p=.032(d=.71)$, consistent with Hypothesis 1c.

Although the Dunnett's test is the most appropriate post hoc test because our main goal was to compare each treatment group to the control group, in the interests of completeness we also conducted Tukey's HSD post hoc tests with alpha set at .05 for the data in Experiment 2 (in Table 4). For Table 4, the firstperson group recalled significantly more important idea units and significantly fewer unimportant idea units than the control group and no other pairwise comparisons were significant. Also, in the interest of completeness, we recalculated each of the foregoing ANOVAS (on transfer and retention) as ANCOVAs with prior knowledge as a covariate (or univariate tests that control for prior knowledge). In each case there was no change in whether the main effect of treatment group was significant.

As in Experiment 1, there is consistent evidence that combining imagination and perspective (i.e., in the first-person perspective group) had a strong effect on helping students learn more deeply than using their normal reading strategy (i.e., in the control group).

Does the first-person perspective group learn more deeply than the third-person perspective group? 
As in Experiment 1, a primary issue concerns whether combining imagination and perspective is more effective than imagination alone. For transfer performance, the first-person perspective group outperformed the third-person perspective group, $t(49)=1.88, p=.033, d=.53$, thus supporting Hypothesis 2a. However, in contrast to Hypotheses $2 b$ and $2 c, t$ tests revealed that the first-person perspective group and the third-person perspective group did not differ significantly for important retention, $t(49)=1.24, p=.220$, or unimportant retention $t(49)=1.45, p=.157$. These results indicate that imagining the blood circulatory system from a first-person perspective leads to better transfer performance than imagining it from a third-person perspective, but does not affect how well learners select important information. Overall, there is evidence that the power of imagination can be increased by adding the power of first-person perspective, but the impact may be limited when there is not support during learning concerning prompts for which components to include in one's images (as was done in Experiment 1).

\section{Does the third-person perspective group learn more deeply than the control group?}

The third hypothesis is that the third-person perspective group will learn more deeply than the control group, indicating that imagination is a powerful learning strategy even when it is not connected with firstperson perspective. In contrast to Hypothesis $3 a$ and the results of Experiment 1, Dunnett's tests revealed that the third-person perspective group did not significantly outperform the control group on the transfer test $(p=.956)$. Similarly, the third-person perspective group did not differ significantly from the control group on important retention $(p=.130)$ or unimportant retention $(p=.141)$, also in contrast to Experiment 1 and Hypotheses $3 \mathrm{~b}$ and $3 \mathrm{c}$. It appears that without the extra support of prompts to tell students which components to include in their images (as was included in Experiment 1), students who are asked to imagine from a third-person perspective do not learn more deeply.

\section{Summary}

The right side of Table 3 summarizes the evidence for each of three hypotheses. In the first row, the firstperson perspective group performed significantly better than the control group on all three measures (as indicated by boldface), and yielded effect sizes in the medium to large range. As in Experiment 1, Hypothesis 1 is supported, pointing to the benefits of combining first-person perspective with imagination to form a powerful learning strategy. In the second row, the first-person perspective group significantly outperformed the control group only on transfer, with a medium effect size, thereby offering partial support for Hypothesis 2 and evidence in line with Experiment 1. In the third row, unlike Experiment 1, the thirdperson perspective group did not significantly outperform the control on any of the measures, perhaps because Experiment 2 did not offer the same level of support for imagination during learning as in Experiment 1.

\section{General Discussion \\ Empirical Contributions}

First, a primary finding is that asking students to use a learning strategy that includes imagination and first-person perspective (i.e., as in the first-person perspective group) helped students learn more deeply from a scientific text describing left-right relations such as involving different sides of the body. Specifically, students who were asked to form images from a first-person perspective as they read outperformed those who read using their normal strategy on transfer, drawing, retaining important material, and ignoring unimportant material, both in Experiment 1 and Experiment 2. This is the clearest and most consistent finding in this study, and the most important new contribution. This is a new contribution because previous studies have not examined the role of the learner's perspective in learning by imagining. 
Second, another primary finding is that asking students to imagine from a first-person perspective was more effective than asking students to imagine from a third-person perspective, in helping students understand the material more deeply as indicated by transfer test performance in Experiments 1 and 2 . However, using a first-person perspective helped learners focus on important material better than using a third-person perspective in Experiment 1 (with high support during learning concerning what to include in one's image) but not in Experiment 2 (with low support). This is an important new contribution, indicating that learning by imagining can be enhanced by adding first-person perspective.

Third, asking students to use a learning strategy that includes imagination but not perspective (i.e., as in the third-person perspective group) partially helped students learn more deeply in Experiment 1, where there was more support during learning in the form of specific prompts for what to include in one's images, but not in Experiment 2, where there was less support during learning. This finding adds to previous research on generative learning strategies (Fiorella \& Mayer, 2015, 2016b), including the conditions under which learning from text is improved when students are asked to make drawings (Leopold \& Leutner, 2012; Schwamborn, Mayer, Thillmann, Leopold, \& Leutner, 2010; Schwamborn, Thillman, Opfermann, \& Leutner, 2011; Van Meter, 2001; Van Meter, Aleksic, Schwartz, \& Garner, 2006) or physically manipulate concrete objects (Glenberg et al., 2011; Marley, Levin, \& Glenberg, 2007, 2010; Marley \& Szabo, 2010; Rubman \& Salatas Waters, 2000).

\section{Theoretical Contributions}

On a theoretical level, we combined imagination and perspective into a single learning strategy in hopes of helping learners shift from a linear reading strategy (in which they read every word without much deep processing) to a generative learning strategy (in which they try to make sense of the material by engaging in the cognitive processes of selecting, organizing, and integrating during learning). Specifically, based on generative learning theory, we designed a learning strategy-reflected in the learning by imagining-aimed at encouraging learners to select components of the text to include in their images, to spatially organize the components in their image, and to translate from words to pictures as a way of integrating the lesson with prior knowledge activated from long-term memory. Based on embodiment theory, we designed a learning strategy-reflected in learning by imagining from a first-person perspective-aimed at encouraging learners to relate the material to their own bodies. More generally, when a lesson requires less transformation in generating a mental image, the learner can engage in more imagining that supports mental model construction.

The findings of Experiments 1 and 2 are consistent with Hypothesis 1 concerning the effectiveness of combining imagination and perspective, and thereby provide support for generative learning theory and embodiment theory from which it is drawn. The findings of Experiments 1 and 2 are consistent with Hypothesis 2 when the focus is on transfer test performance, supporting the superiority of combining imagination and perspective over imagination without first-person perspective. This demonstrates the value of considering the role of embodiment in implementing imagination-based learning strategies. Finally, Hypothesis 3 is somewhat supported in Experiment 1 but not in Experiment 2, suggesting the importance of guiding students' attention during learning (such as by highlighting the key components described in a paragraph). It appears that the act of imagining is challenging and is most effective when students are supported during learning with clear instructions for what to include in one's image.

This work extends theories of embodiment (Barsalou, 2008; Robbins \& Aydede, 2009) to learning from printed text, and is consistent with research demonstrating the role of first-person perspective in learning from instructional video (Fiorella et al., 2017). This work also is consistent with the wider literature on the role of embodiment in education (Glenberg, 2008), which shows that students can use their body as an aid to learning.

\section{Practical Contributions}


The present results, together with other evidence on the imagination effect, suggest imagination can be an effective learning strategy in the context of text-based STEM learning. However, this study demonstrates that the effectiveness of the imagination strategy depends on the way it is implemented in the learning process. In the present study, instructions to take a first-person perspective in forming mental images caused better learning than instructions to take a third-person perspective. Therefore, these results suggest a modification of the imagination principle (Fiorella \& Mayer, 2015; Leopold \& Mayer, 2015), which calls for asking learners to form mental images depicting the content described in a scientific explanatory text. When the scientific text describes a cause-and-effect system with left-right relations (such as how the human heart works), students should be encouraged to form images based on a first-person perspective, that is, from the perspective of their own body. An important practical implication concerns learning about systems that have left-right relations, in which, having one's body aligned with the left-right orientation of the elements in the text can help ensure that imagining is an effective learning strategy. Examples include the human body, electrical circuits, and chemical compounds. This study helps refine and strengthen the imagination principle as an effective learning strategy that can be added to earlier lists of learning strategies (Dunlosky et al., 2013; Miyatsu, Nguyen, \& McDaniel, 2018). This focus on selfreference during cognitive processing also is consistent with alignment effects in spatial navigation, in which people comprehend maps better when the map is in the same orientation as they are (Knauff, 2013).

\section{Limitations and Future Directions}

This was a short term, laboratory study with an immediate test of effects. Future work is warranted to determine the role of imagination and perspective strategies within authentic classroom settings over extended periods of time. Research on learning strategies draws on both laboratory and field studies (Dunlosky et al., 2013; Fiorella \& Mayer, 2015; Miyatsu et al., 2018).

The material was a lesson on the human circulatory system. Future work is warranted to determine whether a first-person perspective is helpful for creating an imagination effect for texts describing different kinds of cause-and-effect systems. For example, other studies have examined how imagination affects learning conceptual systems such as how the respiratory system works (Leopold \& Mayer, 2015) or chemical processes in how soap works (Leutner et al., 2009), or how imagination helps in using spreadsheets (Cooper et al., 2001) or computer programming (Ginns et al., 2003). Further studies also are needed to investigate how other features of mental images apart from the perspective of the reader affect mental model building (e.g., resolution of mental images).

Another limitation is that we did not ensure that students followed directions for imagining during learning and we do not know whether students in the control group formed mental images. Future research should include rigorous techniques for determining treatment fidelity. This can be done via video recording of students during learning, and analyzing the recording to determine the number of pointing gestures per paragraph.

Learners in the first-person perspective group were instructed to point, whereas those in the third-person perspective group were not, so future research is needed to untangle the role of pointing in learning by imagining. The rationale for this instruction is that using a first-person perspective may be less familiar to students; nevertheless, it would be useful to examine whether asking students to point while learning by imagining has useful effects. 
It should be noted that Experiments 1 and 2 differed not only in the level of support and guidance given to students for how to imagine during learning, but they also had several methodological differences including the contents of the tests, the population of participants, and the location of the study. Future research is needed to examine the role of level of support in learning by imagining. For example, Leahy and Sweller (2004) found imagination effects when the instructional materials were well designed but not when they were poorly designed. In order to make direct comparisons concerning the effects of varying the level of support, this should be varied within a single study rather than across studies.

Future work should also examine the role of individual differences in prior knowledge, reading ability, and other characteristics in order to determine whether the treatments are equally effective for all kinds of learners. For example, Leahy and Sweller (2005) and Ginns et al. (2003) reported strong imagination effects for high knowledge learners but not for low knowledge learners. Similarly, Cooper et al. (2001) reported strong imagination effects for higher achieving students but not lower achieving students, as well as for high knowledge learners but not low knowledge learners. Overall, the search for boundary conditions (or moderators) is a worthwhile next step in research on imagination as a learning strategy (Fiorella \& Mayer, 2015).

Finally, the study involved college students, but future work is needed with a larger number of students to determine whether the imagination effect is modulated by the age and type of learners. For example, Cooper et al. (2001) reported imagination effects with middle school students, and Leahy and Sweller $(2004,2005,2008)$ reported imagination effects with elementary schoolchildren. In order to make crossage comparisons, however, it would be useful to compare performance across ages in a single study.

\section{Conclusion}

This set of studies shows that students learn better from a scientific text describing how the circulatory system works when they are asked to imagine illustrations from a first-person perspective that depict the information in the text. Importantly, this work shows that the effectiveness of learning by imagining as a generative learning strategy can be improved by asking learners to imagine from a first-person perspective rather than a third-person perspective. This finding concerning the power of combining imagining and perspective is the main new contribution of this project and has both practical implications for modifying the imagination principle to recommend imagining from a first-person perspective and theoretical implications confirming a prediction of embodiment theory.

\section{References}

Alexander P. A., Grossnickle E. M. (2016). Positioning interest and curiosity within a model of academic development. In K. R. Wentzel, D. B. Miele 0, Handbook of motivation at school (2nd ed., pp. 188-208). New York, NY: Taylor \& Francis. [Context Link]

Barsalou L. W. (2008). Grounded cognition. Annual Review of Psychology, 59, 617-645. SFX Bibliographic Links Library Holdings | [Context Link]

Bartlett F. C. (1932). Remembering. New York, NY: Cambridge University Press. [Context Link]

Biazak J. E., Marley S. C., Levin J. R. (2010). Does an activity-based learning strategy improve preschool children's memory for narrative passages? Early Childhood Research Quarterly, 25, 515-526. SFX Bibliographic Links | Library Holdings | [Context Link]

Bokosmaty S., Mavilidi M.-F., Paas F. (2017). Making versus observing manipulations of geometric properties of triangles to learn geometry using dynamic geometry software. Computers \& Education, 113, 313-326. [Context Link]

Butcher K. R. (2006). Learning from text with diagrams: Promoting mental model development and 
inference generation. Journal of Educational Psychology, 98, 182-197. Ovid Full Text $\mid \underline{\text { SFX }}$ Bibliographic Links | Library Holdings |[Context Link]

Chambliss M. J., Calfee R. C. (1998). Textbooks for learning. New York, NY: Routledge. [Context Link]

Cooper G., Tindall-Ford S., Chandler P., Sweller J. (2001). Learning by imagining. Journal of Experimental Psychology: Applied, 7, 68-82. Ovid Full Text $\mid \underline{\text { SFX }}$ Bibliographic Links $\mid$ Library Holdings $\mid$ [Context Link]

Cromley J. G., Snyder-Hogan L. E., Luciw-Dubas U. A. (2010). Reading comprehension of scientific text: A domain-specific test of the direct and inferential mediation model of reading comprehension. Journal of Educational Psychology, 102, 687-700. Ovid Full Text $\mid$ SFX | Bibliographic Links $\mid$ Library Holdings [Context Link]

Dunlosky J., Rawson K. A., Marsh E. J., Nathan M. J., Willingham D. T. (2013). Improving students' learning with effective learning techniques: Promising directions from cognitive and educational psychology. Psychological Science in the Public Interest, 14, 4-58. SFX $\mid$ Bibliographic Links $\mid$ Library, Holdings | [Context Link]

Fiorella L., Mayer R. E. (2015). Learning as a generative activity: Eight learning strategies that promote understanding. New York, NY: Cambridge University Press. [Context Link]

Fiorella L., Mayer R. E. (2016a). Effects of observing the instructor draw diagrams on learning from multimedia messages. Journal of Educational Psychology, 108, 528-546. [Context Link]

Fiorella L., Mayer R. E. (2016b). Eight ways to promote generative learning. Educational Psychology Review, 28, 717-741. [Context Link]

Fiorella L., van Gog T., Hoogerheide V., Mayer R. E. (2017). It's all a matter of perspective: Viewing firstperson video modeling examples promotes learning of an assembly task. Journal of Educational Psychology, 109, 653-665. Ovid Full Text $|\underline{\text { SFX }}| \underline{\text { Bibliographic Links }} \mid \underline{\text { Library Holdings }}$ |[Context Link]

Gallagher S. (2005). How the body shapes the mind. New York, NY: Oxford University Press. [Context Link]

Gerofsky S. (2010). Mathematical learning and gesture: Character viewpoint and observer viewpoint in students' gestured graphs of functions. Gesture, 10, 321-343. SFX $\mid$ Bibliographic Links $\mid$ Library. Holdings [Context Link]

Ginns P., Chandler P., Sweller J. (2003). When imagining information is effective. Contemporary Educational Psychology, 28, 229-251. SFX $\mid \underline{\text { Bibliographic Links }}$ Library Holdings $\mid$ [Context Link]

Glenberg A. M. (2008). Embodiment for education. In P. Calvo, T. Gomila (), Handbook of cognitive science: An embodied approach (pp. 355-372). San Diego, CA: Elsevier. [Context Link]

Glenberg A. M., Goldberg A. B., Zhu X. (2011). Improving early reading comprehension using embodied

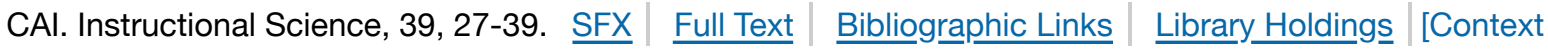
Link]

Glenberg A. M., Gutierrez T., Levin J. R., Japuntich S., Kaschak M. P. (2004). Activity and imagined activity can enhance young children's reading comprehension. Journal of Educational Psychology, 96, 424-436. 
Goldin-Meadow S., Beilock S. L. (2010). Action's influence on thought: The case of gesture. Perspectives

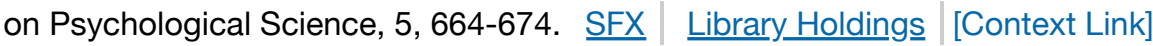

Goldman-Segall R. (2014). Points of viewing children's thinking. New York, NY: Psychology Press. (Original work published 1998). [Context Link]

Goldman-Segall R., Maxwell J. W. (2003). Computers, the Internet, and new media for learning. In W. M. Reynolds, G. E. Miller 0, Handbook of psychology: Vol. 7. Educational psychology (pp. 393-427). Hoboken, NJ: Wiley. [Context Link]

Hegarty M., Waller D. (2004). A dissociation between mental rotation and perspective-taking spatial abilities. Intelligence, 32, 175-191. SFX | Bibliographic Links $\mid$ Library Holdings | [Context Link]

Jackson P. L., Meltzoff A. N., Decety J. (2006). Neural circuits involved in imitation and perspective-taking. Neurolmage, 31, 429-439. SFX | Bibliographic Links | Library Holdings | [Context Link]

Knauff M. (2013). Space to reason: A spatial theory of human thought. Cambridge, MA: MIT Press. [Context Link]

Kontra C., Goldin-Meadow S., Beilock S. L. (2012). Embodied learning across the life span. Topics in Cognitive Science, 4, 731-739. [Context Link]

Leahy W., Sweller J. (2004). Cognitive load and the imagination effect. Applied Cognitive Psychology, 18, 857-875. SFX $\mid \underline{\text { Full Text }}$ Bibliographic Links | Library Holdings $\mid$ [Context Link]

Leahy W., Sweller J. (2005). Interactions among the imagination, expertise reversal, and element interactivity effects. Journal of Experimental Psychology: Applied, 11, 266-276. Ovid Full Text $\mid$ SFX Bibliographic Links | Library Holdings | [Context Link]

Leahy W., Sweller J. (2008). The imagination effect increases with an increased intrinsic cognitive load. Applied Cognitive Psychology, 22, 273-283. SFX $\mid$ Full Text $\mid$ Bibliographic Links $\mid$ Library Holdings [Context Link]

Leopold C., Leutner D. (2012). Science text comprehension: Drawing, main idea selection, and summarizing as learning strategies. Learning and Instruction, 22, 16-26. SFX Bibliographic Links Library Holdings [Context Link]

Leopold C., Mayer R. (2015). An imagination effect in learning from scientific text. Journal of Educational Psychology, 107, 47-63. Ovid Full Text $|\underline{\text { SFX }}| \underline{\text { Bibliographic Links }} \mid$ Library Holdings $\mid$ [Context Link]

Leutner D., Leopold C., Sumfleth E. (2009). Cognitive load and science text comprehension: Effects of drawing and mentally imagining text content. Computers in Human Behavior, 25, 284-289. SFX Bibliographic Links Library Holdings [Context Link]

Lin L., Lee C. H., Kalyuga S., Wang Y., Guan S., Wu H. (2017). The effect of learner-generated drawing and imagination in comprehending science text. Journal of Experimental Education, 85, 142-154. SFX Bibliographic Links Library Holdings [Context Link]

Lindgren R. (2012). Generating a learning stance through perspective-taking in a virtual environment. Computers in Human Behavior, 28, 1130-1139. SFX | Bibliographic Links | Library Holdings $\mid$ [Context Link] 
Lowe R., Ploetzner R. (). (2017). Learning from dynamic visualization. New York, NY: Springer. [Context Link]

Marley S. C., Carbonneau K. J. (2015). How psychological research with instructional manipulatives can inform classroom learning. Scholarship of Teaching and Learning in Psychology, 1, 412-424. [Context Link]

Marley S. C., Levin J. R., Glenberg A. M. (2007). Improving Native American children's listening comprehension through concrete representations. Contemporary Educational Psychology, 32, 537-550. SFX | Bibliographic Links | Library Holdings | [Context Link]

Marley S. C., Levin J. R., Glenberg A. M. (2010). What cognitive benefits does an activity-based reading strategy afford young Native American readers? Journal of Experimental Education, 78, 395-417. SFX Bibliographic Links Library Holdings [Context Link]

Marley S. C., Szabo Z. (2010). Improving children's listening comprehension with a manipulation strategy. The Journal of Educational Research, 103, 227-238. SFX | Bibliographic Links | Library Holdings [Context Link]

Mayer R. E. (2009). Multimedia learning (2nd ed.). New York, NY: Cambridge University Press. [Context Link]

Mayer R. E. 0. (2014a). The Cambridge handbook of multimedia learning (2nd ed.). New York, NY: Cambridge University Press. [Context Link]

Mayer R. E. (2014b). Cognitive revolution and information processing perspective. In D. C. Phillips 0, Encyclopedia of educational theory and philosophy (pp. 142-149). Thousand Oaks, CA: Sage. [Context Link]

Mayer R. E., Wittrock M. C. (2006). Problem solving. In P. Alexander, P. Winne, G. Phye (), Handbook of educational psychology (pp. 287-303). Mahwah, NJ: Erlbaum. [Context Link]

Miyatsu T., Nguyen K., McDaniel M. A. (2018). Five popular study strategies: Their pitfalls and optimal implementations. Perspectives on Psychological Science, 13, 390-407. SFX Library Holdings [Context Link]

Oostendorp H. V., Goldman S. R. 0. (1999). The construction of mental representations during learning. Mahwah, NJ: Erlbaum. [Context Link]

Otero J., Graesser A. C. (). (2002). The psychology of science text comprehension. New York, NY: Routledge. [Context Link]

Pellegrino J. G., Hilton M. L. (). (2012). Education for life and work: Developing transferable knowledge and skills for the 21st century. Washington, DC: National Academies Press. [Context Link]

Piaget J. (1926). The language and thought of the child. London, England: Kegan, Paul, Trench, Trubner, and Company. [Context Link]

Ponce H. R., Mayer R. E. (2014). Qualitatively different cognitive processing during online reading primed by different study activities. Computers in Human Behavior, 30, 121-130. SFX $\mid$ Bibliographic Links Library Holdings $\mid$ [Context Link] 
Pressley M., Woloshyn V. (1995). Cognitive strategy instruction that really improves children's academic performance. Cambridge, MA: Brookline Books. [Context Link]

Rasco R. W., Tennyson R. D., Boutwell R. C. (1975). Imagery instructions and drawings in learning prose. Journal of Educational Psychology, 67, 188-192. Ovid Full Text $\mid$ SFX $\mid$ Bibliographic Links $\mid$ Library. Holdings [Context Link]

Renninger K. A., Hidi S. E. (2016). The power of interest for motivation and engagement. New York, NY: Routledge. [Context Link]

Rizzolatti G., Craighero L. (2004). The mirror-neuron system. Annual Review of Neuroscience, 27, 169-192. [Context Link]

Robbins P., Aydede M. (2009). A short primer on situated cognition. In P. Robbins, M. Aydede 0, The Cambridge handbook of situated cognition (pp. 3-10). New York, NY: Cambridge University Press. [Context Link]

Rubman C. N., Salatas Waters H. (2000). A, B seeing: The role of constructive processes in children's comprehension monitoring. Journal of Educational Psychology, 92, 503-514. Ovid Full Text $\mid$ SFX $\mid$ Bibliographic Links | Library Holdings | [Context Link]

Schwamborn A., Mayer R. E., Thillmann H., Leopold C., Leutner D. (2010). Drawing as a generative activity and drawing as a prognostic activity. Journal of Educational Psychology, 102, 872-879. Ovid Full Text SFX | Bibliographic Links | Library Holdings | [Context Link]

Schwamborn A., Thillmann H., Opfermann M., Leutner D. (2011). Cognitive load and instructionally supported learning with provided and learner-generated visualizations. Computers in Human Behavior, 27, 89-93. SFX Bibliographic Links Library Holdings | [Context Link]

Shapiro L. (). (2014). The Routledge handbook of embodied cognition. New York, NY: Routledge. [Context Link]

Shavelson R. J., Towne L. (2002). Scientific research in education. Washington, DC: National Academy Press. [Context Link]

Stull A. T., Padalkar S., Hegarty M. (2017, ). Augmenting spatial thinking with molecular models in STEM. Presentation at the Annual Conference of the American Educational Research Association, San Antonio, TX. [Context Link]

van Gog T., Paas F., Marcus N., Ayres P., Sweller J. (2009). The mirror neuron system and observational learning: Implications for the effectiveness of dynamic visualizations. Educational Psychology Review, 21, 21-30. SFX | Full Text Bibliographic Links Library Holdings |[Context Link]

Van Meter P. (2001). Drawing construction as a strategy for learning from text. Journal of Educational Psychology, 93, 129-140. [Context Link]

Van Meter P., Aleksic M., Schwartz A., Garner J. (2006). Learner-generated drawing as a strategy for learning from content area text. Contemporary Educational Psychology, 31, 142-166. SFX

Bibliographic Links L Library Holdings | [Context Link]

Vitale J. M., Swart M. I., Black J. B. (2014). Integrating intuitive and novel grounded concepts in a dynamic 
geometry learning environment. Computers \& Education, 72, 231-248. [Context Link]

Wertheimer M. (1959). Productive thinking. New York, NY: Harper \& Row. [Context Link]

Wigfield A., Tonks S. M., Klauda S. L. (2016). Expectancy-value theory. In K. R. Wentzel, D. B. Miele 0, Handbook of motivation at school (2nd ed., pp. 55-74). New York, NY: Taylor \& Francis. [Context Link]

Wittrock M. C. (1974). Learning as a generative process. Educational Psychologist, 11, 87-95. [Context Link]

Wittrock M. C. (1989). Generative processes of comprehension. Educational Psychologist, 24, 345-376. [Context Link]

imagination; perspective; multimedia learning; learning strategy; reading strategy

\section{IMAGE GALLERY}

Select All

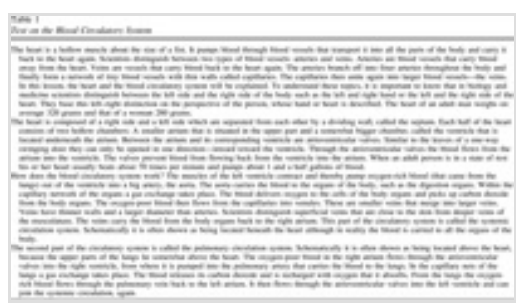

1 Text on the Blood ...

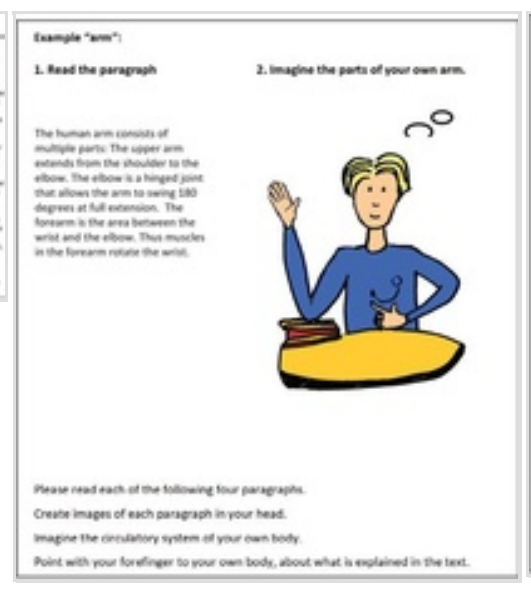

1. Instruction sheet...

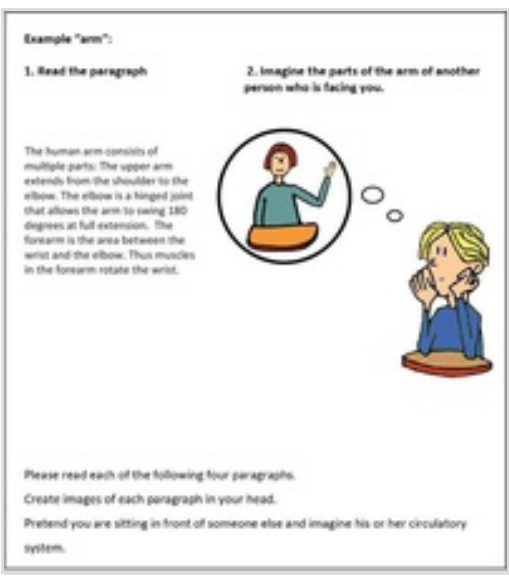

2. Instruction sheet...

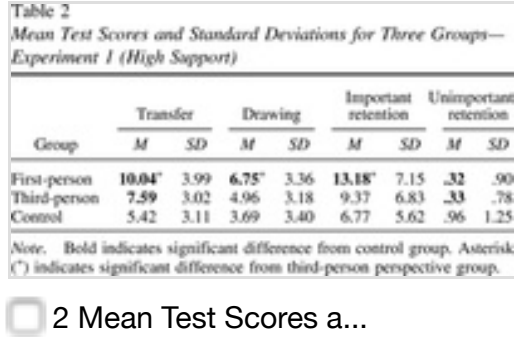

2 Mean Test Scores a...

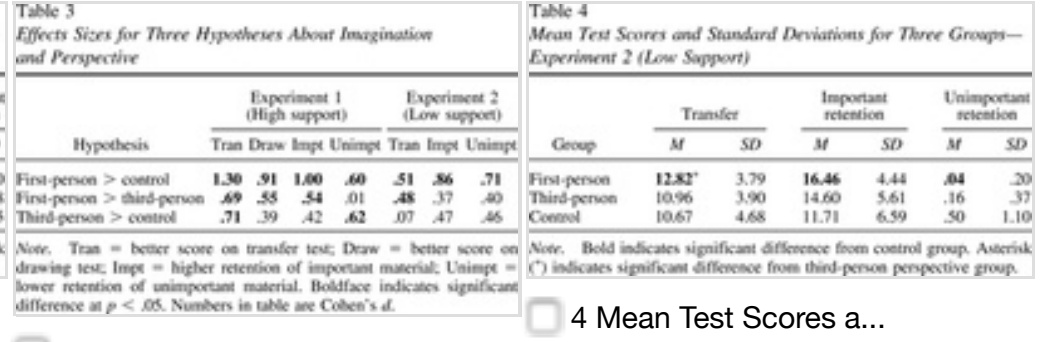

3 Effects Sizes for ... 
(C) 2019 Ovid Technologies, Inc. All rights reserved. OvidUI_04.02.01.008, SourcelD HEAD 